WIENER SLAVISTISCHES JAHRBUCH, Band 53/2007, 73-78

(C) 2007 by Österreichische Akademie der Wissenschaften, Wien

VERA SMOLE

\title{
Delež avstrijske slovenistike pri Slovenskem, Slovanskem in Evropskem lingvističnem atlasu
}

Der Beitrag der österreichischen Slowenistik zur linguistischen Geographie besteht zu einem Teil in den monographischen Bearbeitungen einzelner Dialekte oder Dialektteile, d. h. örtlicher Mundarten (P. Zdovc, K. Sturm-Schnabl, L. Karničar), am stärksten zum Tragen kommt er aber in einem der Teilziele des großen, noch nicht zur Gänze realisierten Projekts „Lexikalische Inventarisierung der slowenischen Volkssprache in Kärnten“, konkret in der Feststellung des Verlaufs einzelner Isolexen. Die österreichische Slowenistik hat sich gelegentlich auch an slowenischen linguistisch-geographischen Projekten beteiligt, vor allem am Obščeslavjanskij lingvističeskij atlas (OLA) und am Atlas Linguarum Europae (ALE), eine größere Zusammenarbeit wäre aber auch beim Slowenischen linguistischen Atlas (SLA) höchst wünschenswert, da von 36 geplanten Punkten im österreichischen Teil Kärntens 8 Punkte noch gar nicht und weitere 3 nur zum Teil aufgezeichnet sind, obwohl bereits 2008 der erste Band des SLA zur Lexik und Wortbildung im semantischen Feld „Mensch“ erscheinen soll.

1. Tako eno- kot večjezični lingvistični atlasi so po pravilu obsežni, kompleksni in dolgoročni projekti. Prostorski, vsebinski in časovni obseg je na eni strani odvisen od zastavljenih ciljev atlasa, malokdaj pa se je možno izogniti zunanjim dejavnikom, kot so število razpoložljivih in ustrezno usposobljenih sodelavcev, zmožnost in obstoj pripomočkov za tehnično izvedbo ter finančno stanje raziskovalne ustanove, kjer se projekt izvaja. Pri večjezičnih atlasih lahko k temu dodamo še nujnost takega političnega stanja v sodelujočih državah, da sodelovanje poteka nemoteno, pri enojezičnem, t. i. nacionalnem atlasu, pa je ravno tako potrebna ustrezna družbena klima, ki stroko v njenih prizadevanjih podpre vsaj na stopnji zaključevanja projekta, tj. pri digitalizaciji zbranega gradiva, analiziranju, kartografiranju in komentiranju oziroma neposredno pred začetkom izdajanja posameznih zvezkov. S problemi pri vseh naštetih zunanjih dejavnikih so se od same ideje dalje srečevali in se še srečujejo vsi trije atlasi: enojezični Slovenski lingvistični atlas (dalje SLA), atlas sorodnih jezikov - Obščeslavjanskij lingvističeskij atlas (Slovanski lingvistični atlas, dalje OLA) in atlas raznorodnih jezikov - Atlas Linguarum Europae (Evropski lingvistični atlas, dalje ALE). 
Že od prvih dialektoloških raziskav slovenskega jezika sredi 19. stoletja dalje je znano - zvezki OLA npr. to samo še potrjujejo -, kako zelo so slovenska narečja razcepljena na vseh jezikovnih ravninah, še posebej pa na glasoslovni, kar bi za njihovo zadovoljivo raziskanost in intenzivnejše delo pri lingvogeografskih projektih terjalo veliko večje število dialektologov, kot jih je ali jih je kdaj koli bilo na Inštitutu za slovenski jezik Frana Ramovša ZRC SAZU v Ljubljani, na katerem se vsi trije projekti (so)izvajajo. Tako je bilo na intenzivnejših in časovno zamejenih stopnjah dela pri vseh atlasih treba poiskati zunanje sodelavce, ki so lahko v svojem raziskovalnem ali bivalnem okolju učinkoviteje izvajali zamudne in zahtevne terenske raziskave ter znali zbrano gradivo ustrezno komentirati. Med izredno kvalitetne zunanje sodelavce štejemo tudi predstavnike avstrijske slovenistike iz treh pedagoško-raziskovalnih centrov, in sicer iz univerz v Celovcu, Gradcu in na Dunaju - to so: Ludvik Karničar, Herta Maurer-Lausegger, Gerhard Neweklowsky in Pavel Zdovc, ki so gradivo na terenu po vprašalnicah zapisovali. Prav tako pa so pomembna vsa druga krajša in daljša dialektološka dela, ki jezikovne pojave natančno beležijo, pojasnjujejo in prostorsko opredeljujejo.

2. V nadaljevanju bodo na kratko predstavljeni vsi trije atlasi in delež avstrijske slovenistike pri nastajanju posameznih projektov.

2.1. Slovenski lingvistični atlas (SLA). ${ }^{1}$ Zasnoval ga je leta 1934 Fran Ramovš, terensko delo pa se je začelo takoj po drugi svetovni vojni. Po manjših preureditvah (ki še niso dokončne) je nastala mreža točk s 406 kraji in vprašalnica z 870 oštevilčenimi vprašanji, med katerimi nekatera vsebujejo tudi popolne ali delne paradigme oz. odgovore z več leksemi/oblikami, tako da je njihovo število blizu številki 3000 . Do sedaj ni izšel še noben zvezek tega atlasa, zbranega pa je 90\% gradiva, objavljenih okrog 60 kart s komentarji in pripravlja se prvi leksično-besedotvorni zvezek s semantičnim poljem »človek « s predvidenim izidom v letu $2008{ }^{2}$ Celotno vprašalnico za SLA je leta 1980 v točki 29 Ebriach/Obirsko zapisal Ludvik Karničar, Herta Maurer-Lausegger pa je leta 1985 opravila tri delne zapise vprašalnice za SLA v krajih 10 Maria Gail/Marija na Zilji, ${ }^{3} 20$ Maria Rain/Žihpolje in 21 Ebenthal/Žrelec.

2.2. Obščeslavjanskij lingvističeskij atlas (OLA). ${ }^{4}$ Tudi ta atlas ima že dolgo zgodovino: od zamisli leta 1929 (A. Meillet in L. Tesnère), ustanovitve iniciativne

${ }^{1}$ Največ točk iz mreže za SLA (skupno jih je 36) sta na avstrijskem Koroškem zapisala Tine Logar (17) in Ivan Grafenauer (9), žal pa ostaja še vedno 8 točk nezapisanih in 3 delno zapisane.

2 Več podatkov o njem je moč najti v Benedik 1999, Kenda-Jež 1999, Smole - Weiss 2003, Smole 2006.

3 Zapisovalka je prispevala tudi sinhron in diahron opis tega govora, glej Lausegger 1989.

4 Pri OLA je z zapisom vprašalnice v hrvaški točki na Gradiščanskem 147a Schandorf/Čemba v letih 1972-1974 sodeloval tudi Gerhard Neweklowsky, ki je naredil tudi vse tri fonološke opise hrvaških gradiščanskih čakavskih govorov, zajetih v mrežo krajev za 
skupine leta 1938 in nato v začetku šestdesetih let še Komisije OLA pri Mednarodnem slavističnem komiteju z organizacijskim središčem v Moskvi pod vodstvom akad. R. I. Avanesova ter nacionalnih komisij, izida fonetične transkripcije in Vprašalnika OLA leta 1965 s 3454 vprašanji iz glasoslovja, naglasa, oblikoslovja, besedotvorja, besedja, pomenoslovja in skladnje, določitve mreže krajev s pribl. 850 točkami, terenskega dela v letih 1965-1975 do uvodnega zvezka atlasa leta 1978 je minilo skoraj 50 let, do izida prvega rednega zvezka leta 1988 pa še 10 let več. ${ }^{5}$ Slovenska narečja so vanj vključena s 25 raziskovalnimi točkami (1-21, 146, 147, 148 in 149): 18 jih je znotraj meja Slovenije, po 3 so na slovenskem etničnem ozemlju v Italiji in Avstriji ter 1 na Madžarskem. Podjunsko točko OLA 148 Grafenbach/Kneža je leta 1971 zapisal Pavel Zdovc. ${ }^{6}$

2.3. Atlas Linguarum Europae (ALE) ${ }^{7}$. ALE je bil ustanovljen leta 1970 pod pokroviteljstvom organizacije UNESCO kot prvi in doslej edini vseevropski raziskovalni projekt na področju sodobnega jezikoslovja. Dobra podlaga mu je bil prav OLA, čeprav je prostorsko ter po številu jezikov in narečij veliko obsežnejši. Mreža ALE obsega 2631 točk, slovenskih točk je 8 (po ena v Italiji in Avstriji, druge v Sloveniji), 7 je izbranih iz mreže raziskovalnih točk OLA, druga kot v OLA je prav slovenska točka v Avstriji, in sicer ALE 02/102 Bilčovs/Ludmannsdorf, ki jo je leta 1980 zapisal Gerhard Neweklowsky v sodelovanju z Antonom Schellandrom in Michaelom Sablatnikom. Zapisovalec je opisal tudi glavne fonetične značilnosti tega govora in na koncu dodal lekseme, ki so za slovensko dialektologijo zanimivi z glasoslovnega, besedotvornega in leksičnega vidika (prim. Neweklowsky 1980).

3. Lingvistični atlasi zahtevajo poleg zemljepisne predstavitve razširjenosti posameznega jezikovnega pojava (ponavadi) v posameznih besedah tudi morfonemsko (pri leksično-besedotvornih zvezkih) ali glasoslovno analizo gradiva kot osnovo za kartografiranje in jezikoslovno interpretacijo $\mathrm{v}$ obliki komentarjev, ki so podlaga interdisciplinarnim branjem kart. $^{8} \mathrm{~V}$ pomoč temu so dragoceni fonološki opisi posa-

OLA (poleg 147a Schandorf/Čemba še 146a Stinatz/Stinjaki in 148a Baumgarten/Pajngrt), kar je seveda prispevek k hrvaški lingvistični geografiji.

5 Do sedaj so izšli še naslednji zvezki OLA: iz fonetično-gramatične serije: I Refleksy *ě, Beograd, 1988, IIa Refleksy *e, Moskva, 1990, IIb Refleksy *o, Wrocław, 1990, III Re-

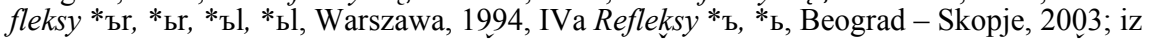
leksikalno-besedotvorne serije pa: 1 Životnyj mir [Živalski svet], Moskva, 1988, 2 Životnovodstvo [Živinoreja], Warszawa, 2000, 3 Rastitel'nyj mir [Rastlinski svet], Minsk, 2000, 8 Profesii i ob̌šcestvennaja žizn' [Poklici in družbeno življenje], Warszawa, 2003. Več podatkov je na: http://ola.zrc-sazu.si.

${ }^{6} \mathrm{Na}$ avstrijskem Koroškem sta še točki 146 Potschach/Potoče in 147 Frießnitz/Breznica pri Šentjakobu v Rožu.

7 V letih 1975-1979 so izšli trije uvodni zvezki tega atlasa, od leta 1983 naprej pa prvih sedem zvezkov z zemljevidi in komentarji; vsi zvezki obravnavajo leksiko.

8 Še vedno se pojavljajo t. i. napisni atlasi, ki ob številki (ali imenu) kraja prinašajo samo odgovor na zastavljeno vprašanje in so metodološko zastareli, čeprav so lahko gradivsko izredno bogati. 
meznih krajevnih govorov, monografske predstavitve tako krajevnih govorov kot narečij ali delov narečij, narečni (delni ali popolnejši) slovarji in tudi vsa druga dialektološka literatura. Po tej strani, posredno torej, pa je delež avstrijske slovenistike neprimerno večji kot ga izkazujejo neposredna sodelovanja pri zgornjih lingvogeografskih projektih. S tega vidika spadajo med pomembnejše prispevke $\mathrm{k}$ slovenski lingvistični geografiji še spodaj našteta dela. ${ }^{9}$

3.1. Ugotovitve potekov posameznih izoleks so bile eden od ciljev raziskovalnega projekta Delovne skupine za slovenistiko Inštituta za slavistiko Univerze v Grad$\mathrm{cu}^{10}$ pod vodstvom Stanislava Hafnerja in Ericha Prunča, ki sta delne rezultate predstavila pod naslovom Lexikalische Inventarisierung der slowenischen Volkssprache in Kärnten (Hafner - Prunč 1980). Delu je pridano 12 znakovnih leksičnih kart ${ }^{11}$ ter osnovna karta in karta uporabljene literature in virov. Mreža točk določa 220 krajev, razporejenih od vzhoda proti zahodu, na nobeni od kart pa ni podatkov za vse kraje. Gradivo je bilo zbrano s pomočjo zapisanih vprašalnic in tonskih (avdio)posnetkov; slednje je zapisano v fonetični transkripciji. Osnovna ugotovitev avtorjev je, ,da obe skupini izoglos (izolekse in izofone) ne sovpadata, da pa je tudi geografska razširjenost raziskanih izoleks zelo različna" (Hafner - Prunč 1980: 324). Projekt se je naprej razvijal predvsem leksikografsko. ${ }^{12}$ Nova spoznanja $\mathrm{v}$ zvezi z izoleksami, do katerih je prišel Ludvik Karničar (sedanji vodja projekta), ki je kartografiral še dodatnih 20 leksemov (krompir, koruza, gozd, dvorišče, klet, veža, pivo, klop, gostilna, butara, žegnanje, solzice, zidar, rebro, drožje, česen, slišati, vojna, voder in kosec; karte niso objavljene) in upošteval razširjenost posameznih leksemov tudi v narečjih na slovenski strani meje, ${ }^{13}$ lahko strnemo takole:

1) kljub različnemu poteku je izolekse mogoče razvrstiti v 10 najbolj pogostih tipov;

2) najpogostejši poteki izoleks odražajo nekdanje komunikacijske prostore, ki ne sovpadajo z današnjimi narečnimi mejami, določenimi na osnovi izofon;

${ }^{9}$ Upoštevana so tista dela, katerih vsebina se ujema z vsebinami (vprašalnicami) predstavljenih lingvističnih atlasov in tako tudi $\mathrm{z}$ naslovom tega prispevka; prispevek avstrijske slovenistike k slovenski dialektologiji (pa tudi imenoslovju in etimologiji) v celoti pa je sorazmerno z veliko večjim številom del, kot jih je tu omenjenih, še veliko večji.

10 Arbeitsgruppe für Slowenistik des Instituts für Slawistik der Universität in Graz.

11 Kartografirani leksemi, za katere sta gradivo in komentar v poglavju 5, legende pa na kartah, so: K. 1: domov - nach Hause, K. 2: teden - Woche, K. 3: grd - hässlich, K. 4: moliti - beten, K. 5: pomlad - Frühling, K. 6: zelje - Kraut, K. 7: zajtrk - Frühstück, K. 8: žep Hosentasche, K. 9: govoriti - sprechen, K. 10: polnočnica - Mette, K. 11: teloh - Schneerose, K. 12: zvonček - Schneeglöcklein.

12 Avtorja sta izdala še 4 knjižna dela: leta 1982 je najprej izšel Schlüssel zum „Thesaurus der slowenischen Volkssprache in Kärnten ", nato še Thesaurus der slowenischen Volkssprache in Kärnten 1: A- bis B-, 1987; 2: C-dn, 1992; 3: do-F, 4: $G-H, 1994$, vse Wien: Verlag der Österreichischen Akademie der Wissenschaften (Sonderpublikation). Po daljšem mirovanju projekta je v začetku leta 2007 pod strokovnim vodstvom L. Karničarja 5. zvezek pripravila Andrejka Žejn: $I-K a$.

13 Karničarjev članek je nastal na izhodiščih ugotovitah H. Pfandla (prim. Pfandl 1981). 
3) potek izoleks ima najpogostejšo smer sever - jug;

4) najodločilneje so nanje vplivale cerkvene in upravne enote;

5) dinamika širjenja izoleks deluje predvsem od vzhoda proti zahodu (Karničar 1999). ${ }^{14}$

3.2. Poleg natančnega sinhronega in diahronega opisa glasoslovja in naglasa jugovzhodnih podjunskih govorov prinaša monografija Pavla Zdovca Die Mundart des Südöstlichen Jauntales in Kärnten: Lautlehre und Akzent der Mundart der "Poljanci” (Zdovc 1972) tudi 9 glasoslovnih kart z obravnavanega področja, ki bodo dragoceno vodilo pri določanju poteka teh izofon tudi na glasoslovnih kartah SLA.

3.3. Veliko elementov lingvistične geografije vsebuje tudi monografija Ludvika Karničarja Der Obir-Dialekt in Kärnten: Die Mundart von Ebriach/Obirsko (Karničar 1990), ki razmeji razlikujoče se jezikovne pojave - poleg glasoslovnih še veliko leksičnih - med samimi krajevnimi govori obirskega narečja ter tistimi iz rožanskega selškega govora (Zell/Sele).

3.4. S samega roba slovenskega etničnega prostora je še neobjavljena ${ }^{15}$ disertacija Katje Sturm-Schnabl Die slovenischen Mundarten und Mundartreste im Klagenfurter Becken (Sturm-Schnabl 1973) s sinhronim in diahronim opisom glasoslovja in zelo bogatim komentiranim besedilnim gradivom iz štirih vasi v Celovški kotlini.

4. Ob koncu lahko ugotovimo, da je prispevek avstrijske slovenistike k lingvistični geografiji deloma zajet v monografskih obdelavah narečij ali njihovih delov (krajevnih govorov) in da se le-tej najbolj približa v enem od delnih ciljev velikega graškega projekta Lexikalische Inventarisierung der slowenischen Volkssprache in Kärnten, tj. ugotovitev potekov posameznih izoleks, ki pa še ni do konca uresničen. Avstrijska slovenistika se je občasno vključila tudi v slovenske lingvogeografske projekte, zlasti v mednarodna projekta OLA in ALE, za večje sodelovanje pri Slovenskem lingvističnem atlasu pa kakor da je zmanjkalo volje, časa ali sredstev: kar 8 točk popolnoma in 3 točke ${ }^{16}$ deloma od načrtovanih 36 točk na avstrijskem Koroškem so do danes (in morda za vselej?!) ostale nezapisane, čeprav naj bi v letu 2008 izšel težko pričakovani prvi leksično-besedotvorni zvezek SLA s semantičnim poljem »človek«.

${ }^{14}$ Ta spoznanja avtor nadgrajuje še z ugotovitvami o sinonimiji in plastitvi slovenskega besedja na Koroškem, ki poleg slovenskih vsebuje nekaj predslovanskih besed, slovanske arhaizme ter neslovenske nemške in na zahodu romanske prevzete besede (Karničar 2006).

15 Dopolnjena $z$ novimi besedili in prevedana $v$ slovenščino (torej dvojezično) se pripravlja za izid pri Založbi ZRC (ZRC SAZU) v Ljubljani.

16 To so točke 14 Teholica/Techelsberg, 22 Timenica/Timenitz, 23 Radiše/Radsberg, 25 Mohliče/Möchling, 30 Bela/Vellach, 31 Lepena/Leppen, 34 Grebinj/Griffen, 35 Ruda/Ruden ter z delnimi zapisi 10 Marija na Zilji/Maria Gail, 20 Žihpolje/Maria Rain in 21 Žrelec/Ebenthal. 
Benedik 1999: $\quad$ F. Benedik, Vodnik po zbirki narečnega gradiva za Slovenski lingvistični atlas (SLA), Ljubljana

Hafner - Prunč 1980: S. Hafner - E. Prunč (ur.), Lexikalische Inventarisierung der slowenischen Volkssprache in Kärnten (Grundsätzliches und Allgemeines), v: Slowenistische Forschungsberichte, ur. S. Hafner (= Slowenistische Forschungsberichte 1), Graz, 59-347

Karničar 1990: L. Karničar, Der Obir-Dialekt in Kärnten: Die Mundart von Ebriach/ Obirsko im Vergleich mit den Nachbarmundarten von Zell/Sele und Trögern/Korte (Phonologie, Morphologie, Mikrotoponymie, Vulgonamen, Lexik, Texte) (= Sitzungsberichte / Österreichische Akademie der Wissenschaften, Philosophisch-Historische Klasse 551), Wien

Karničar 1999: $\quad$ L. Karničar, Aktualnost slovenskih narečij na Koroškem in tipologizacija izoleks, in: Logarjev zbornik. Referati s 1 . mednarodnega dialektološkega simpozija v Mariboru, ur. Z. Zorko in M. Koletnik (= Zora 8), Maribor, 204-213

Karničar 2006: $\quad$ L. Karničar, Iz koroške poljedelske leksike, v: Diahronija in sinhronija $\mathrm{v}$ dialektoloških raziskavah, ur. M. Koletnik in V. Smole, Maribor 2006, 320-327

Kenda-Jež 1999: $\quad$ K. Kenda-Jež, Predgovor, v: F. Benedik, Vodnik po zbirki narečnega gradiva za Slovenski lingvistični atlas (SLA), Ljubljana, 5-9

Lausegger 1989: $\quad$ H. Lausegger, Značilnosti slovenskega govora pri Mariji na Zilji, v: Zbornik razprav iz slovanskega jezikoslovja: Tinetu Logarju ob sedemdesetletnici, ur. F. Jakopin, Ljubljana, 137-148

Nartnik 1998: V. Nartnik, Pet zvezkov ALE, Jezikoslovni zapiski 4, 181-185

Neweklowsky 1980: G. Neweklowsky, Die slowenische Mundart von Ludmannsdorf (Bilčovs) in Kärnten, v: Klagenfurter Beiträge zur Sprachwissenschaft 6, 103-113

Pfandl 1981: $\quad$ H. Pfandl, K regionalni porazdelitvi izoleks v slovenskih narečjih na Koroškem, Slavistična revija 29/4, 449-452

Smole - Weiss 2003: V. Smole - P. Weiss, Dialektologische Forschungen am Fran-Ramovš-Institut für Slowenische Sprache des Wissenschaftlichen Forschungszentrums der Slowenischen Akademie der Wissenschaften und Künste in Ljubljana, Dialectologia et Geolinguistica 11, 110-120

Smole 2006: V. Smole, Prvi zvezek Slovenskega lingvističnega atlasa: realnost ali utopija?, v: Diahronija in sinhronija v dialektoloških raziskavah, ur. M. Koletnik in V. Smole, Maribor, 226-234

Sturm-Schnabl 1973: S. K. Sturm-Schnabl, Die slovenischen Mundarten und Mundartreste im Klagenfurter Becken, disertacija, Wien

Zdove 1972: P. Zdovc, Die Mundart des südöstlichen Jauntales in Kärnten: Lautlehre und Akzent der Mundart der „Poljanci“ (= Schriften der Balkan-Kommission, Linguistische Abteilung / Österreichische Akademie der Wissenschaften 20), Wien

\author{
Vera Smole \\ Inštitut za slovenski jezik Frana Ramovša \\ ZRC ZAZU, Novi trg 4, SI-1000 Ljubljana \\ Oddelek za slovenistiko, Filozofska fakulteta \\ Univerze v Ljubljani, Aškerčeva 2, SI-1000 Ljubljana \\ vera.smole@guest.arnes.si
}

